\title{
Peculiarities of Alloying Effect on the Eutectic Cementite Behavior Under Hot Rolling
}

\author{
Tatiana Mironova \\ The National Metallurgical Academy, Ukraine \\ Svetlana Proidak \\ Dnipropetrovsk National University of Railway Transport, Ukraine
}

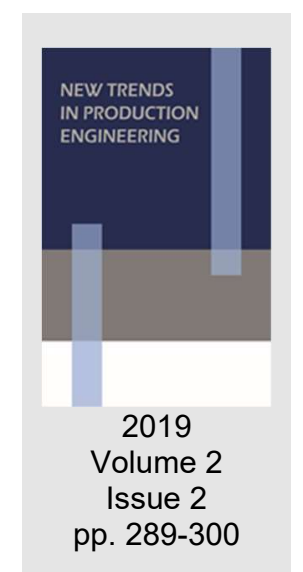

Date of submission to the Editor: 09/2019

Date of acceptance by the Editor: 11/2019

\section{INTRODUCTION}

At present, cast iron remains one of the major modern casting materials both in metallurgy and machine-building industry. Chilled cast iron is widely applied as a material with increased wear resistance. This is due to the presence of eutectic carbides in the chilled cast iron structure that provide its high hardness. Nonetheless, the eutectic dislocation in the shape of a net around the primary austenite dendrites decreases the impact hardness and increases the tendency to brittle fracture. Alloying with the carbide forming elements, such as chromium, vanadium, titanium, etc., may alter the morphology of eutectic colonies and their dislocation in the structure, but to achieve that, the content of these elements should be at least 10\% (Taran-Zhovnir Yu.N., 1998, .Silman, G.I.; Makarenko, K.V. 2010, Silman, G.I 1992, Dojka, M et al., 2018, Jiang et al., 2017, BedollaJacuinde, A et al., 2005, Guo Erjun et al., 2009, Maja, M. E. et al., 2016, Liu et al., 2016, Bedolla-Jacuinde et al., 2015). One of the most effective means of the eutectic alloy product shape and microstructure transformation is hot plastic working in the process of which the eutectic net crushing occurs. Chilled cast iron properties are fundamentally improved after hot plastic working: ductility, strength and impact hardness increase by 2-3 times on retention of the high hardness factor (Taran-Zhovnir Yu.N., 1998, LI, et. al.,1991, Zhang et al., 2010, Sukhanov D.A. et al., 2017, Mironova T.M. \& Kutsova V.Z., 2009)

However, hot plastic working of chilled cast iron has not been widely applied in metallurgy. At that, the determinative factor is the reduced ductility of eutectic carbides, especially iron carbide, which is a parent phase in the low-alloy chilled cast iron eutectic. The formation of cracks in the places of the ledeburite colonies dislocation precedes the carbide network breaking and causes the destruction of the blanks, when they are subjected to plastic deformation.

The increase of the chilled cast iron ductility can be obtained when using phase transformations in eutectic cementite under the chilled cast iron lean alloying with carbide forming elements. The latter, dissolving in eutectic cementite, increase its metastability, and, during high-temperature annealing, form their 
own $\mathrm{MeC}$ or $\mathrm{Me}_{7} \mathrm{C}_{3}$ type carbides. At that, partial decarbonization of cementite contributes to austenite formation. Phase transformations of this kind break the eutectic cementite density and facilitate its crushing under deformation.

Such carbide transformations can be observed in metastable carbides of rapid steels (Taran, Y.N. et. al., 1981, Mironova T.M. et. al., 2012)

Consequently, the purpose of the paper is to study the alloying effect on the chilled cast iron ductility and the eutectic cementite behavior under hot rolling.

\section{METHODS}

The cast iron hot rolling was carried out with the help of the laboratory DUO 300 rolling mill. The range of reduction under study is $17 \% \ldots 65 \%$ and the initial deformation temperature was $1050^{\circ} \mathrm{C}$. After passing through the pair of rolls, the samples were quenched in the water. The composition of the rolled billets is given in Table 1, and the eutectic cementite content in these alloys is represented in Table 2.

Table 1 Chemical composition of the rolled cast iron billets

\begin{tabular}{|c|c|c|c|c|c|c|c|}
\hline \multirow{2}{*}{ Alloy No. } & \multicolumn{7}{|c|}{ Content of elements, \% by weight } \\
\cline { 2 - 8 } & $\mathrm{C}$ & $\mathrm{Cr}$ & $\mathrm{V}$ & $\mathrm{Mn}$ & $\mathrm{Si}$ & $\mathrm{S}$ & $\mathrm{P}$ \\
\hline 1 & 2.98 & 0.54 & - & 0.17 & 0.34 & 0.034 & 0.051 \\
\hline 2 & 3.01 & 4.02 & - & 0.25 & 0.41 & 0.031 & 0.052 \\
\hline 3 & 3.03 & 8.01 & - & 0.41 & 0.35 & 0.029 & 0.054 \\
\hline 4 & 2.93 & 0.68 & 0.54 & 0.23 & 0.44 & 0.030 & 0.050 \\
\hline 5 & 2.91 & 0.57 & 1.39 & 0.18 & 0.42 & 0.031 & 0.050 \\
\hline 6 & 2.92 & 0.59 & 2.51 & 0.21 & 0.44 & 0.032 & 0.052 \\
\hline
\end{tabular}

Table 2 Chemical composition of eutectic cementite of the alloys in experimental production

\begin{tabular}{|c|c|c|c|c|}
\hline Alloy No. & $\mathrm{Fe}$ & $\mathrm{Cr}$ & $\mathrm{V}$ & $\mathrm{Mn}$ \\
\hline 1 & 92.45 & 1.05 & - & 0.15 \\
\hline 2 & 86.03 & 7.98 & - & 0.24 \\
\hline 3 & 79.9 & 15.1 & - & 0.18 \\
\hline 4 & 90.48 & 0.86 & 2.08 & 0.22 \\
\hline 5 & 87.45 & 0.78 & 4.76 & 0.17 \\
\hline 6 & 86.95 & 1.05 & 4.83 & 0.19 \\
\hline
\end{tabular}

The phase composition of the alloys under examination as well as the type of carbides in the cast structure, that are precipitated as a result of the solid-phase reactions under heat treatment, were determined by means of the X-ray structure analysis.

When determining the cementite texture formation in cast irons in initial condition and after hot rolling, the X-ray photography from the polished sections was applied; the polished sections were produced parallel to the rolling plane (RP) and perpendicular to the rolling direction. To calculate the inverse pole figures (IPF), the data, obtained when photographing the texture less specimen, were used.

The X-ray pattern identification was carried out with respect to the cementite interplane distances data (Andrews K, 1971, Lipson R.G., N.I. Petcy, 1940, Hume-Rozery W., Raynor, A.T., 1942). To design the inverse pole figures, the integrated intensity of the reflections was measured when taking the X-ray 
photogram by means of diffractometer DRON-3.0 UM in the Fe-Ka radiation with the regular focusing by Bragg-Brentano.

\section{RESULTS}

The structure of the chromium-doped alloys (alloy No. 1-3 Table 1) is composed of austenite (decomposition products) and ledeburite; the latter contains cementite alloyed in varying degrees (Table 2). According to the microstructure analysis and the X-ray analysis of crystal structure, in the alloys (No. 1-3) in eutectic cementite, the formation of new phases has not been observed when exposed both to the temperature and deformation. Nonetheless, chromizing affects the cementite properties. Thus, prior to the deformation, the microhardness of $(\mathrm{Fe}, \mathrm{Cr})_{3} \mathrm{C}$ carbide increases more than $30 \%$ and $40 \%$ in the alloys No. 2 and No. 3 as compared to the low-alloyed cementite in the alloy No. 1 (Fig. 1). In its turn, chromium, strengthening the covalent constituent of the interatomic bindings in cementite, enhances its hardness.

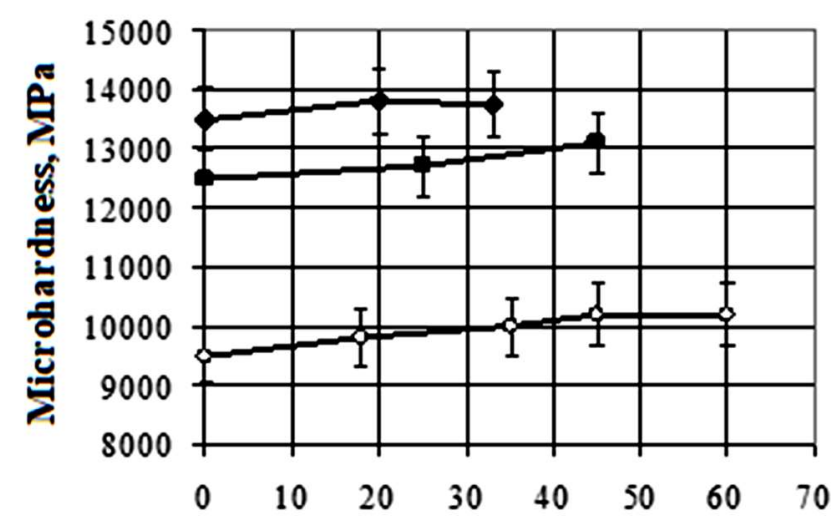

Deformation degree of cast iron, $\%$

$-\circ-$ alloy No. 1; - - alloy No. 2;- - alloy No. 3

Fig. 1 The effect of the degree of eutectic cementite alloying with chromium on its microhardness in relation to deformation degree

Before plastic deformation and after preannealing, cementite is textured in all alloys. In the alloys No. 2 and No. 3 the texture is very weak: almost a similar set of planes is parallel and perpendicular to the heat dissipation at crystallization, though some of the planes, such as the plane (200), are 2.5 times different in terms of the pole density.

Hot rolling causes the eutectic cementite multicomponent texture formation, which is different from its primary texture (Pirogova E.V. et. al., 1990).

The planes (021), (122), $(004,023)$ are the most quick-responsive to the texturing for cementite alloyed with chromium, regardless of its concentration.

The texture formation depends on the prevailing dynamic structure formation mechanism. After hot working, it is possible to fix some preferred orientations that are characteristic of some structure formation processes, related to hot-cold work and dynamic softening (Pirogova E.V. et. al., 1990). Dynamic recrystallization, on the one hand, can cause strengthening of the deformation 
texture and its constituents, and, on the other hand, can lead to the basically different texture formation. Due to the interaction of these possible variants, the preferred orientations of any kind may totally disappear. The mechanism of the preferred orientation formation can be more precisely defined by the breadth alternation of the corresponding X-ray interferences of cementite $(\beta)$. At the same time, the dynamics of the pole densities (PD) redistribution has been studied. The quantity $\beta$ depends on the two competing processes of the crystal lattice defects changing. They are the increase caused by cold work hardening, and the decrease, resulting from the softening caused by the high temperature. In the least chromium-alloyed cementite in the alloy $\mathrm{No} .1\left(1,05 \% \mathrm{Cr}\right.$ in $\left.\mathrm{Me}_{3} \mathrm{C}\right)$, the breadth of the X-ray interferences almost does not react to the deformation degree increase (Fig. 2a). There occurs the insignificant redistribution of the intensities and the parent texture blurring. In this alloy, cementite undergoes dynamic recrystallization under all studied deformation degrees, however, heat hardening prevails in the orientations (122) and (021).

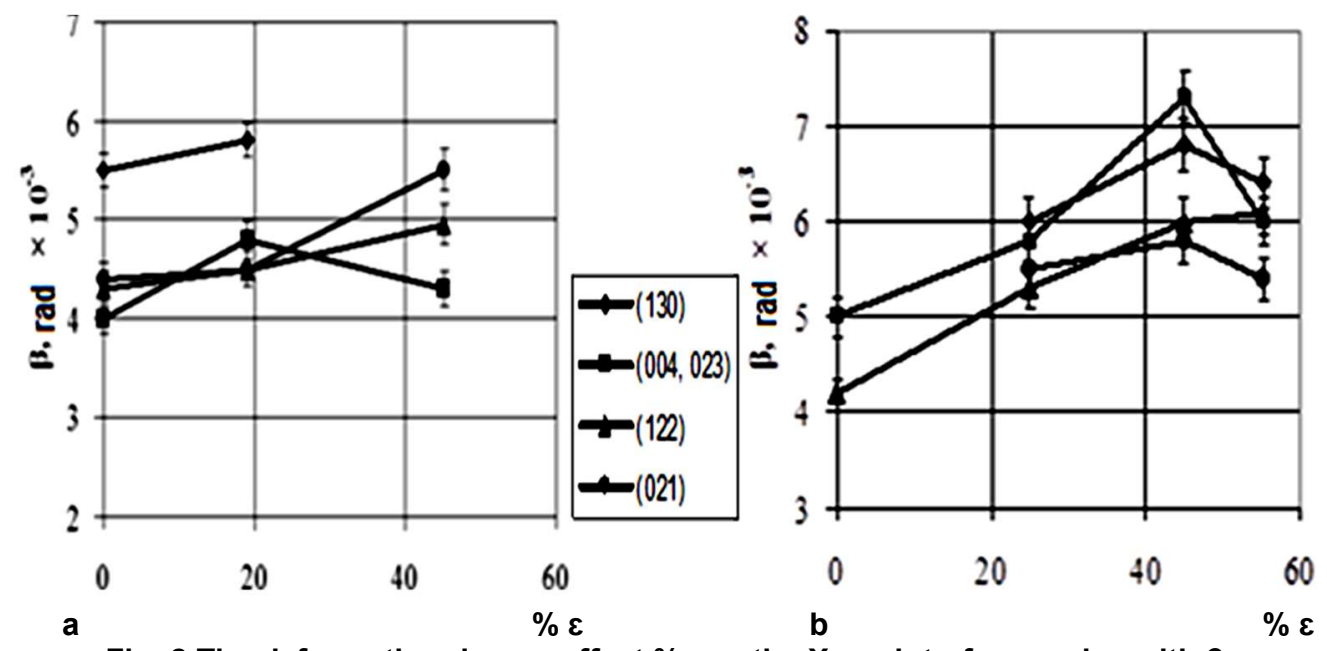

Fig. 2 The deformation degree effect $\% \varepsilon$ on the X-ray interference breadth $\beta$ in cementite with $1,05 \% \mathrm{Cr}(\mathrm{a})$ and $7.98 \% \mathrm{Cr}(\mathrm{b})$ content

The increase of the degree of cementite alloying with chromium obstructs deformation and restricts its dynamic recrystallization. Cementite, containing $7.98 \%$ of chromium, is characterized of more intense $\beta$ alternation. By the humps of these curves, one can judge about the structural change mechanism alternation. Such hump is observed in the planes $(130),(021),(004,023)$ at the deformation degree of $45 \%$ (Fig. 2b). This fact proves the dynamic softening occurrence, and, most probably, the dynamic recrystallization. At these deformation degrees, the general decrease of the pole density and the cementite defectiveness are observed. However, the plane (122) is the exception. The growth of the pole plane is observed in crystals, in which the plane (122) is parallel to the rolling plane. This growth is followed by the increase of $\beta$. That is to say, at this type of orientation of the plane (122), cold work hardening is predominant in cementite crystals under all studied degrees of deformation $(25 \% \ldots 60 \%)$. 
Alloying with chromium inhibits the dynamic recovery and recrystallization in iron carbide at hot working. The X-ray structural analysis results show, that alloyed cementite undergoes hardening and softening similar to the substitutional solid solutions, in which the alloying element increases the energy of atomic interactions and strengthens the covalent constituent of the interatomic bindings.

In the study, the evaluation of the dislocation density $\rho$ in cementite by the integral values of the lines breadth $(\beta)$ measured with XRD patterns has been carried out. When attaining the $\rho$ quantity of $10^{9} \mathrm{~cm}^{-2}$ in the low-alloyed cementite, recrystallization is developing and even cementite fission is observed along the formed boundaries (Fig. 3a,b); under the increased chromium concentration in cementite, the dynamic softening does not occur (Fig. 3b), and only glide lines are visible.

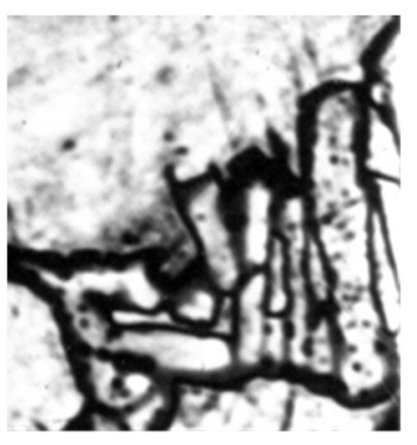

a

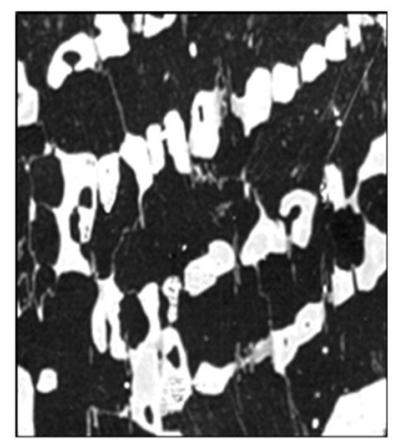

b

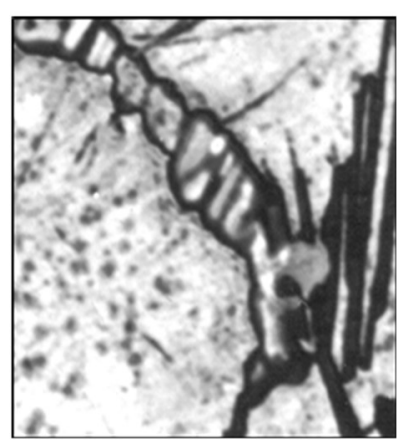

C

Fig. 3 The behavior of eutectic cementite alloyed with chromium under hot working, $\times$ 1000: a, b - alloy No. 1; c - alloy No. 3

At cold work hardening of cementite, the rolling texture is being formed with the main components (122), (021), (023). The deformation component (130) is peculiar to the alloys containing more than $3 \% \ldots 4 \%$ of $\mathrm{Cr}$.

The iron carbide alloying with chromium reduces its hardenability under deformation; the dynamic recrystallization is also restrained, that in general deteriorates chrome iron ductility and steels containing ledeburite. In eutectic cementite, alloying with vanadium causes phase transformations that stimulate the cast iron ductility increase. Carbide transformation affects both the hardening and softening, as well as cementite behavior under hot working. Vanadium, when entering the metallic sublattice of cementite and having higher covalent bond energy as compared to that of chromium, increases iron carbide hardness even more actively (Fig. 4a).

In the alloy No. 5, the intense growth of cementite microhardness is caused by the disperse vanadium carbides formation during preannealing and as hot-rolled (Fig. 4b). 

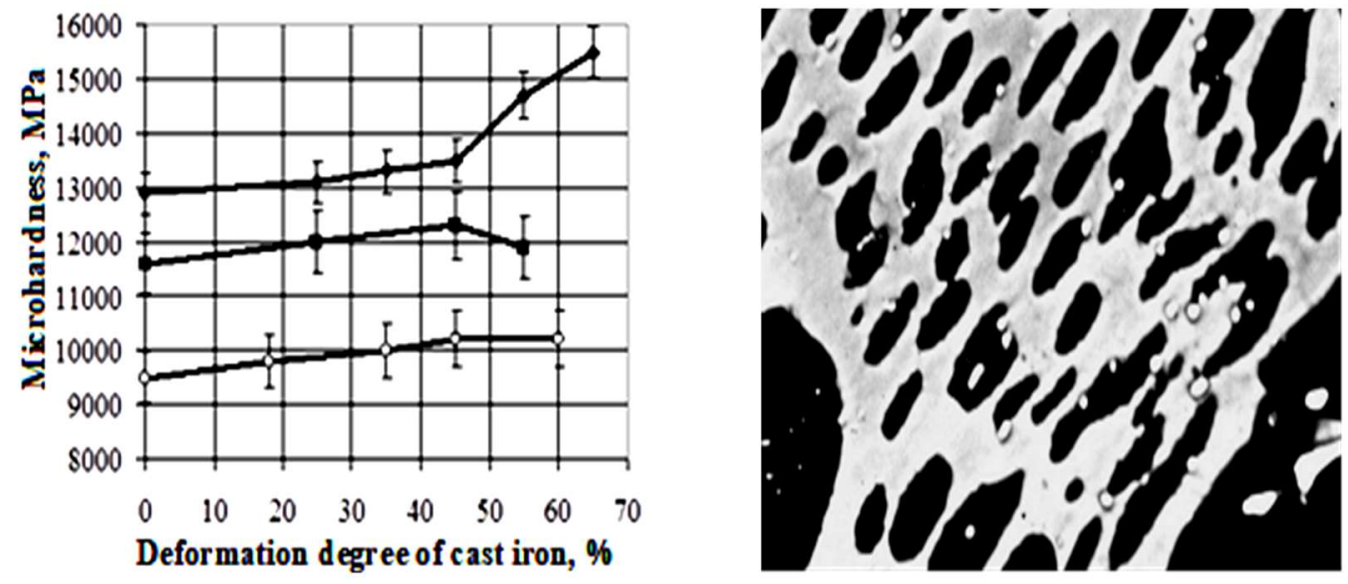

——alloy No. $1 ; \longrightarrow$ alloy No. $4 ;-\multimap$ alloy No. 5;

a

b

Fig. 4 Effect of vanadium and deformation degree on cementite microhardness

(a) and vanadium carbides precipitation in ledeburite, $\times 1200$

Cementite alloying with vanadium up to $\sim 2 \%$, i.e. in an amount insufficient for VC precipitation, appears to be equivalent to appending of $8 \%$ chromium into carbide $\mathrm{Me}_{3} \mathrm{C}$ (alloy No. 2). In all studied ranges of deformation, hot-cold work is the predominant type of structure formation, when the degree of alloying with vanadium is increased. It emerges as a simultaneous growth of the most texturesensitive elements (021), (122), (023), (222) in the pole density and the increase of the dislocation density in them. The line breadth (122) is preserved at the same level at reduction of $45 \%$ and $65 \%$ (Fig. 5).

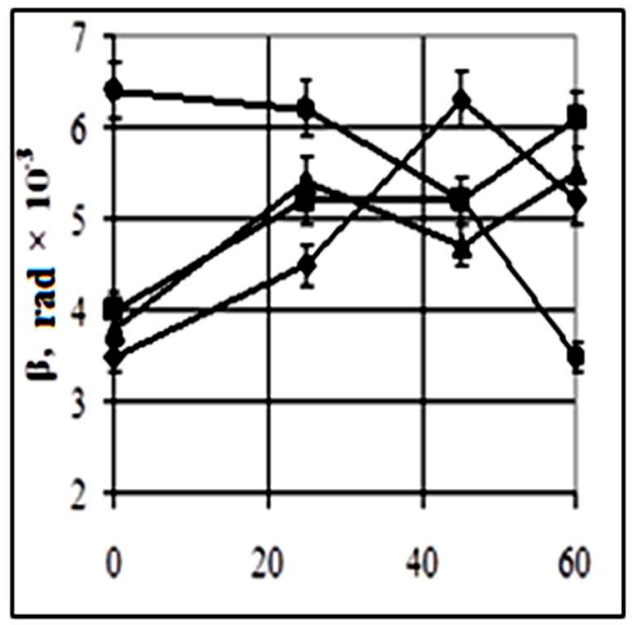

a

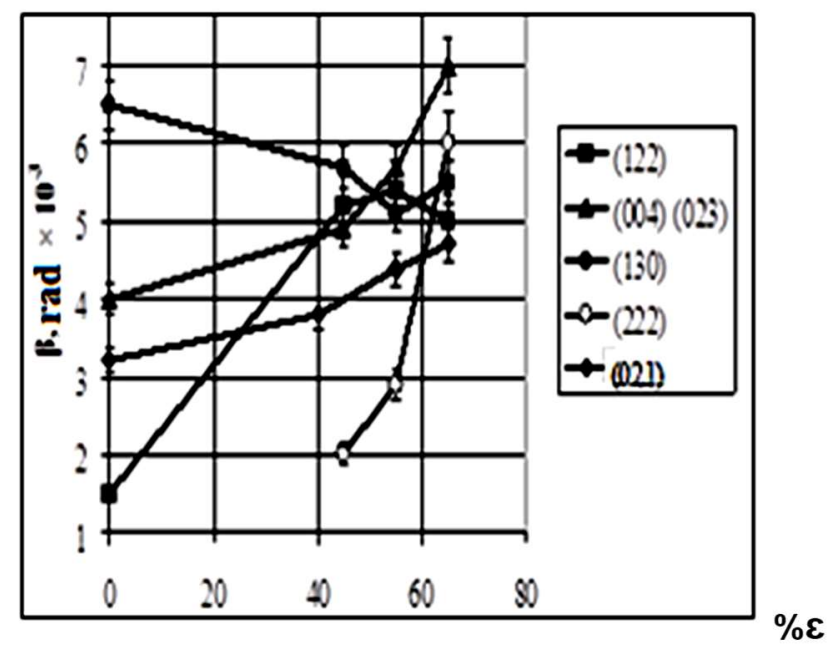

b

Fig. 5 Effect of the alloy deformation degree on the X-ray interferences breadth $\beta$ : $a$ - for the alloy No. 4; $b$ - for the alloy No. 5 .

Thus, the dynamic recovery occurs in cementite with this preferred orientation. The content of vanadium in eutectic cementite, that does not cause its subsequent decomposition with the more stable new phases formation, restrains dynamic recrystallization, while the carbide transformation development changes the pole density distribution and is followed by the additional rolling texture element (222) strengthening as related to other alloys (Fig. 6). Carbide particles VC are formed at the preannealing stage. 

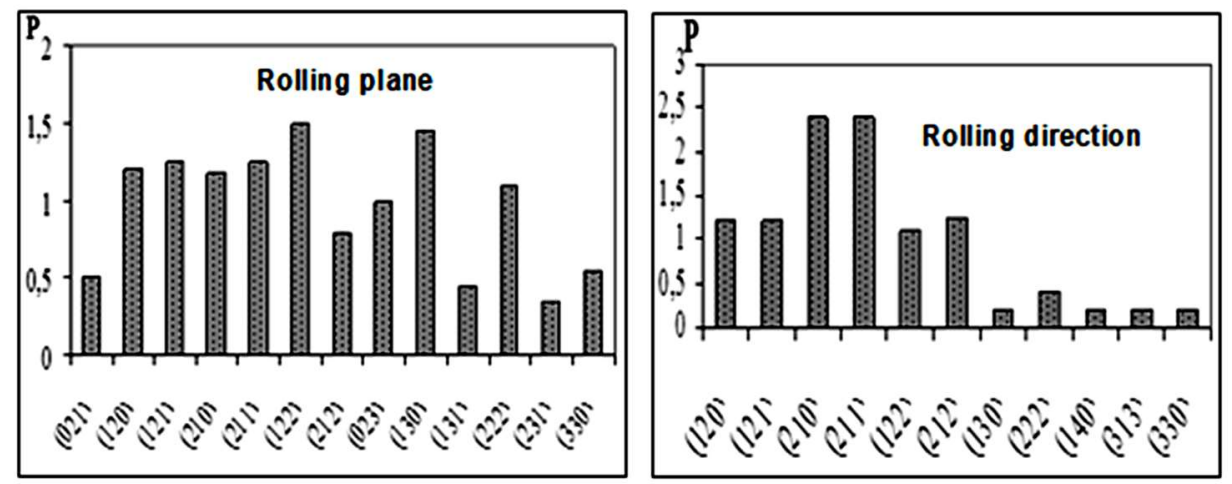

a
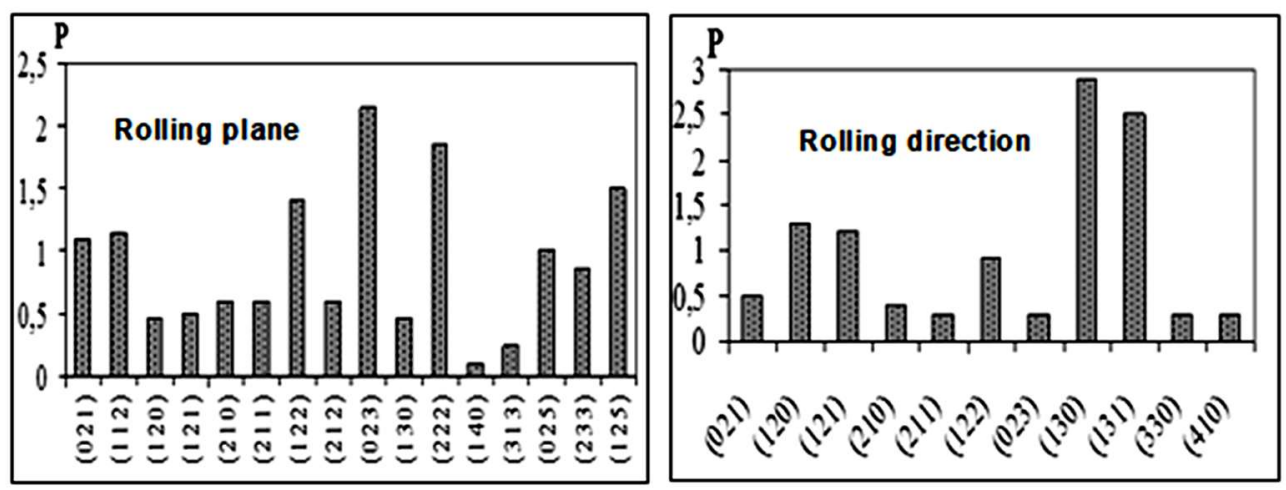

b

Fig. 6 Effect of the alloy No. 5 deformation degree on the eutectic cementite pole plane distribution at different deformation degrees (Rolling plane is perpendicular to heat dissipation and Rolling direction is parallel to heat dissipation): $a-\varepsilon=25 \% ; b-\varepsilon=65 \%$

The piling-ups of dislocations are being formed and the stresses, exceeding the critical values $\sigma$ of shear in iron carbide, occur under deformation in austenite at the crystal boundaries of vanadium-supersaturated cementite. In the cementite surface layer, there are dislocations that form glide lines, in which particles of stable carbide phase VC are precipitated (Fig. 7).

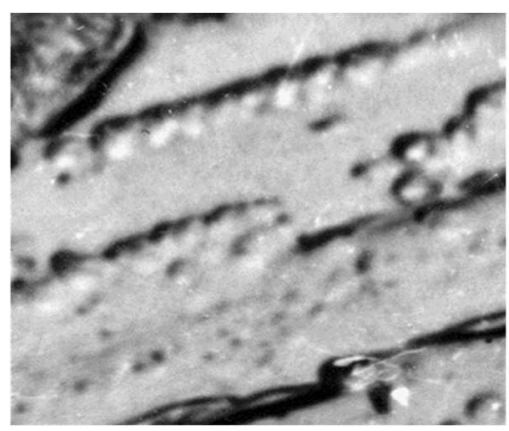

a

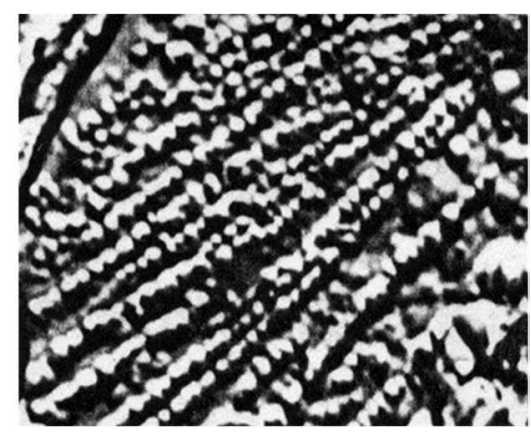

b

Fig. 7 Precipitation of VC carbides in cementite under hot rolling, $\times 2000$ : a - electrolytic etching; $b$ - ionic etching

The X-ray analysis results have shown, that, under hot rolling in supersaturated cementite, precipitation of vanadium carbides stimulates the extra glide plane $\{111\}$ occurrence.

The presence of VC crystals in the cementite crystals increases external influences on cementite; at that, the stresses, that induce the dislocation 
generation in cementite, are enhanced. Thus, the transformation under analysis is similar to the autocatalytic reactions, related to the caused by the reaction dislocation forming.

The difference is that the stresses, caused by the VC crystals precipitation, are insufficient to form dislocations in cementite when there are no external stresses. Such phase transformation interactions with plastic deformation can lead to the anomalous ductility increase.

\section{DISCUSSION}

According to the research, during hot rolling, deformation stimulates phase transformations in vanadium-alloyed cementite. Similar cases have been studied in academic literature (Osipov K.A, 1949, Tsobkallo O.S., 1957, Wu et al., 2018, Cerri et al., 2017, Barnes, A., 2007, Figueiredo et al., 2008). The same characteristics are peculiar to the superplastic effect development, induced by metastability of the phases at magnesium-copper, tin-lead, aluminum-silver and other eutectics deformation (Presnyakov A.A., 1969). Bochvar suggested studying the superplastic effect at the metastable alloy deformation as the interaction of stabilization and deformation: without deformation no anomalies have been detected in the alloy behavior, and in the absence of metastability, deformation is anomaly-free (Bochvar A.A., 1948). Only the interaction of these two processes predetermines the superplastic effect development. In experimental cast irons, where cementite is supersaturated with vanadium, its metastability is increased, while the precipitation of vanadium carbides decreases metastability. During hot working, such transformation is more intensive, but, at the same time, cementite ductility is anomalously increased. At the first stages deformation occurs in austenite. Due to the different orientation of eutectic colonies, the subsequent deformation transfer begins only in some of them. In some cases, the special slewing of ledeburite biocrystals occurs in the first place (Fig. 8), while deformation affects only satisfactory regions of eutectic cementite.

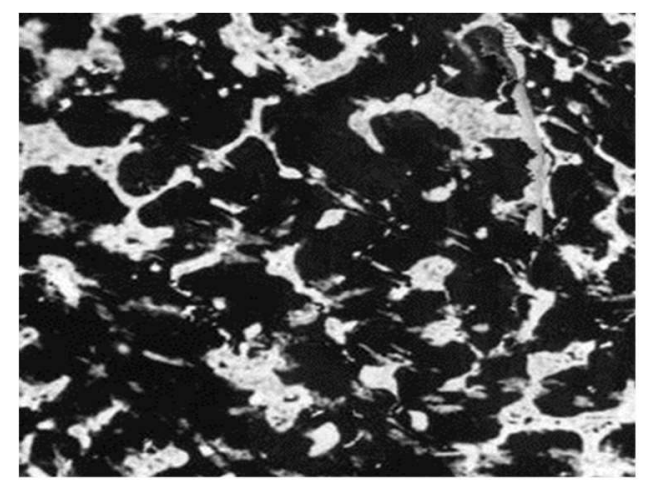

a

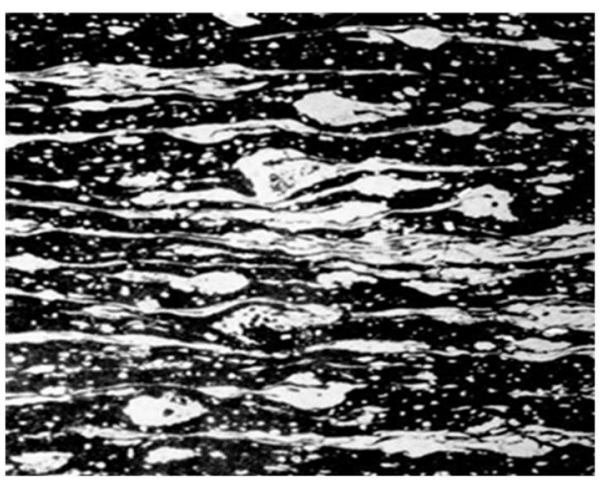

b

Fig. 8 Ledeburite shape change under rolling, $\times 200$ :

$\mathbf{a}$ - before deformation; $\mathbf{b}$ - after deformation

That is why, in this case it would be inappropriate to report the homogeneous deformation as a sign of superplastic flow within the sample. However, a 
presumable ledeburite colony, that simultaneously undergoes tensile stresses in the rolling plane and compressive stresses in the normal direction to this plane, would have such a sufficient change of the shape, so that it could be compared to the sample shape change during the plastic flow.

As homogenous deformation can be observed due to super plasticity (necking does not occur at tension), a scale factor becomes significant for ductility indices. On condition that a ledeburite colony is a working part of the sample exposed to tension, it can be stated, that a micro superplastic effect is observed in some structural biocrystals (Fig. 8). Ledeburite colonies are pulled out without destruction.

In this case, the behaviour of these structural aggregates corresponds to the characteristics and regularities peculiar to the samples, whose structure allows the super plasticity occurrence. The extraordinarily high ductility of ledeburite is provided by the transition from the metastable condition to a stable one in eutectic colonies due to the transformation in the vanadium-alloyed cementite under the "extreme" plastic deformation conditions.

\section{CONCLUSIONS}

It has been found out, that during hot working $\mathrm{Fe}_{3} \mathrm{C}$ carbide can harden to the degree sufficient for the dynamic recovery and recrystallization. At that, in the course of alloying with chromium, these processes diminish in cementite, while carbide ductility, as well as cast iron ductility in general, decrease. Alloying with vanadium in an amount that does not cause phase transformation in cementite, i.e. less than $2 \%$, stimulates cementite hardening under hot rolling, but restrains dynamic recrystallization. The multiple glide planes in cementite $\{130\},\{011\},\{112\}$ have been determined. Moreover, it has been proved, that in the supersaturated cementite, vanadium carbides precipitation stimulates the extra glide plane $\{111\}$ occurrence during hot rolling. The deformation texture forming in eutectic cementite under hot rolling has been detected. This process is connected with the dynamic softening and depends on the degree and the nature of its alloying. Under hot working, the effect of the vanadium-alloyed iron carbide lubricating is observed due to the proeutectoid constituents precipitation. Finally, ledeburite colonies are pulled out without destruction and crushing.

\section{REFERENCES}

Andrews K., Dyson D., Keown S. (1971). Elektronogrammy i ikh interpretatsiya [Electron-diffraction patterns and their interpretation- Moskow: Mir, p. 256.

Barnes, A. J.Superplastic forming 40 years and still growing (2006) Conference: Materials Science and Technology Conference and Exhibition. Journal of Materials Engineering and Performance. Volume 16 , Issue 4, pp. 440-454. Published: AUG 2007. DOI: $10.1007 / \mathrm{s} 11665-007-9076-5$

Bedolla-Jacuinde, A.; Guerra, F. V.; Mejia, I. (2015). Abrasive wear of V-Nb-Ti alloyed high-chromium white irons. Conference: 20th International Wear of Materials Conference (WOM) Location: Toronto, CANADA Date: APR 12-16, Volume: 332 pp. 1006-1011. 
Bedolla-Jacuinde, A; Correa, R; Quezada, JG; et al. (2005). Effect of Titanium on the As-Cast Microstructure of a $16 \%$ Chromium White Iron. Materials Science and Engineering A-Structural Materials Properties Microstructure and Processing. Volume 398, Issue 1-2, pp. 297-308. Available at: https://doi.org/10.1016/j.msea.2005.03.072.

Bochvar A.A. (1948). O raznykh mekhanizmakh plastichnosti $v$ metallicheskikh splavakh [On the problem of different ductility mechanisms in metal alloys]. Izvestiia Akademii nauk SSSR. No. 5, pp. 56-58.

Cerri, E.; Knez, D.; Rimoldi, T.; et al. (2017) Microstructure evolution and mechanical properties of hot deformed Mg9A11Zn samples containing a friction stir processed zone. JournaL of Magnesium and Alloys. Volume 5, Issue 4, pp. 388-403 https://doi.org/10.1016/j.jma.2017.11.003.

Dojka, M.; Kondracki, M.; Studnicki, A.; et al. (2018). Crystallization Process of High Chromium Cast Iron with the Addition of $\mathrm{Ti}$ and $\mathrm{Sr}$. Archives of Foundry Engineering. Volume 18, pp. 57-64.

Figueiredo, Roberto B.; Langdon, Terence G. (2008). Record superplastic ductility in a magnesium alloy processed by equal-channel angular pressing. Advanced Engineering Materials. Volume: 10, pp. 37-40. Available at: https://doi.org/10.1002/adem.200700315

Guo Erjun; Wang Lihua; Wang Liping; et al. (2009)/ Effects of RE, V, Ti and B Composite Modification on the Microstructure and Properties of High Chromium Cast Iron Containing 3\% Molybdenum. Rare Metals. Volume 28, pp. 606-611.

Hume-Rozery W., Raynor, A.T. (1942). Journal. I.S.I. Volume145 (143), pp. 93-117.

Jiang, Jipeng; Li, Shibo; Li, Haolin; et al. (2017). Effect of in Situ Formed TiCx Grains on the Microstructural Modification of High Chromium White Iron/ Journal of Alloys and Compounds, Volume 726 (5), pp. 430-436. Available at: https://doi.org/10.1016/j.jallcom.2017.07.274.

LI, H; Wang, YM; Burdett, CF. (1991). Hot Deformation-Behavior and Ledeburite Refinement Mechanism for Hypoeutectoid Low-Alloy White CasT Irons. Materials Science and Technology. Volume 7, pp. 660-664. Available at: https://doi.org/10.1179/mst.1991.7.7.660

Lipson R.G., N.I. Petcy. (1940). Journal. I.S.I. Volume 142 (95), pp 79-85. Available at: http://ena.lp.edu.ua:8080/handle/ntb/15406

Liu, Hai-yun; Song, Zhi-liang; Cao, Qing. (2016). Microstructure and Properties of FeCr-C Hardfacing Alloys Reinforced with TiC-NbC. Journal of Iron and Steel Research International. Volume 23 (3), pp. 276-280. Available at: DOI: 10.1016/S1006-706X (16)30045-0

Maja, M. E.; Maruma, M. G.; Mampuru, L. A.; et al. (2016). Effect of Niobium on the Solidification Structure and Properties of Hypoeutectic High-Chromium White Cast Irons. Journal of the SoutherN AfricaN Institute of Mining and Metallurgy. Volume 116, pp. 981-986. Available at:DOI: 10.17159/2411-9717/2016/v116n10a14

Mironova T.M., Donskaya T.R. Sidorova.A.Yu. (2012). O mekhanizmakh vliyaniya fazovykh perekhodov na povedenie evtekticheskikh karbidov pri deformirovanii [On the problem of mechanisms of phase changes effect on the eutectic carbides behavior at deformation] Visnyk Dnipropetrovskoho universytetu. Physics. Radioelectronics, 20(2), pp. 97-104.

Mironova T.M., Kutsova V.Z. (2009). Struktura i svoistva deformiruemykh chugunov. Dnepropetrovsk. Driant. $190 \mathrm{p}$.

Osipov K.A. (1949).O mekhanizme plastichnosti gomogennykh splavov pri vysokikh temperaturakh [On the problem of ductility mechanism of homogeneous alloys at high temperatures] Izvestiia Akademii nauk SSSR, no. 9,pp. 38-41.

Pirogova E.V. (1990) Strukturnye izmeneniya $v$ cementite belykh chugunov pri goryachey plasticheskoy deformatsii [Structural changes in the white iron cementite under hot plastic deformation]. Composition and mechanical properties of metallic materials: collection of scientific papers. . Leningrad: L. D. Nauchnotekhnicheskoy Propagandy, pp. 85-87. 
Presnyakov A.A. (1969) Sverkh plastichnost metallov i splavov [Superplasticity of metals and alloys] Nauka Kazakhskoy SSR, Alma-At:, p. 209.

Silman, G.I.; Makarenko, K.V. (2010). Some Features of Eutectic Structure Formation in Cast Iron. Metal Science and Heat Treatment, Volume 52 (7-8), pp.316-320.

Silman, G.I (1992).Phase-Diagram of the FE-C-V System and Its Application to Metallography of Steels and Cast Irons. Metal Science and Heat Treatment, Volume 34 (11-12), pp. 665-670.

Sukhanov D.A., Arhangelskiy L.B., Plotnikova N.V., Sukhanova L.N., Golikov A.Yu. (2017) White Cast Iron Plastic Deformation. Obrabotka metallov (tekhnologiya, oborudovanie, instrumenty) -Metal Working and Material Science, . 4 (77), pp. 4354. Available at: doi: 10.17212/1994- 6309-2017-3-43-54.

Taran-Zhovnir, Yu.N. (1998) Stroenie evtektik i sozdanie novykh splavov evtekticheskogo tipa [Structure of eutectics and creation of new alloys of eutectic type] Modern linguistics of the XXI century. 1sted. Pohodnya, I.K.: Kyiv, Naukova dumka, pp. 176-197.

Taran, YN; Nizhnikovskaya, PF; Mironova, TM. (1981). Structural-Changes in Eutectics In R6M5 Steel During Hot Plastic-Deformation. Steel in the USSR. pp. 296-298.

Tsobkallo O.S., Latsh V. V. (1957). Rentgenograficheskiy analiz struktury alyuminiya $i$ latuni L70 [The X-ray test of aluminium and brass $\int 70$ structure] Izvestiia Akademii nauk SSSR, No. 3 ,pp. 28-32.

Wu, Zhicheng; Sandloebes, Stefanie; Rao, Jing; et al. (2018). Local Mechanical Properties and Plasticity Mechanisms in a Zn-Al Eutectic Alloy. Materials \& Design. $\begin{array}{lllll}\text { Volume } & 157 & \text { pp. } & 337-350 . & \text { Available }\end{array}$ https://doi.org/10.1016/j.matdes.2018.07.051

Zhang, Jianjun; Gao, Yimin; Xing, Jiandong; et al. (2010). Effects of Forging and Heat Treatment on Microstructure and Properties of High Boron White Cast Iron. Conference: 9th International Symposium on Science and Processing of Cast Iron Location: Luxor, EGYPT Date: NOV 10-13,. Central Metallurg Res \& Dev Inst. Science and processing of Cast Iron IX .Book Series: Key Engineering Materials Volume 457, pp. 225-230. Published 2011, Available at: https://doi.org/10.4028/www.scientific.net/KEM.457.225 


\begin{abstract}
.
Currently, cast iron remains one of the major modern casting materials in metallurgy and machine-building industry and is sure to take the lead in the future. Chilled cast iron has high hardness and wear resistance due to a large number of carbide phases in its structure. However, low ductility and impact hardness essentially limit its applicability in terms of processing. Hot plastic working, under which the eutectic net crushing is observed, appears to be one of the most effective means of the eutectic alloy products shape and microstructure transformation. Chilled cast iron properties fundamentally improve after hot plastic working: ductility, strength and impact hardness increase by 2-3 times on retention of the high hardness factor. Chilled cast iron ductility increase can be attained when using phase transformations in eutectic cementite under lean alloying with carbide forming elements. The purpose of the paper is to study alloying effect on the chilled cast iron ductility as well as eutectic cementite behavior under hot rolling. In the paper hardening and softening of the structural components in chilled cast iron under hot working have been studied. The deformation texture forming in eutectic cementite under hot rolling has been revealed, which is connected with the dynamic softening and depends on the degree and the nature of its alloying. The mechanism and regularities of the phase transformation effect in cementite on its behavior under plastic deformation and on the alloys ductility in general have been studied. In cementite chromium alloying initiates processes, that can be characterized as the pre-precipitation stage of the new phases, and this way it contributes to the cast iron ductility reduction and embrittles cementite. Carbide transformation, that occurs in eutectic cementite under alloying with vanadium, stimulates softening of the alloy and increases its ductility level. Moreover, the multiple glide planes $\{130\},\{011\},\{112\}$ in cementite have been determined. It has been found out, that in supersaturated cementite vanadium carbides precipitation stimulates the extra glide plane $\{111\}$ occurrence under hot rolling. The essence of the carbide transformation phenomenon is that under hot working there occurs the lubricating effect at the transition of the metastable iron carbide condition, which is strengthened with vanadium supersaturation and mechanical hardening, to a more stable condition due to precipitation of the proeutectoid constituents on the one hand, and because of the dynamic softening processes on the other hand. At that, the autocatalyticity effect is observed: there is precipitation of carbides with hardening and softening, similar to the processes that arise as a result of the superplastic effect induced by phase transformations.
\end{abstract}

Keywords: cast iron, cementite, deformation, phase transformations, ductility 